\title{
A STUDY OF IMMIGRATION IN THE TEACHING OF AMERICAN HISTORY -A CASE STUDY OF TIBETAN IMMIGRANTS IN THE UNITED STATE
}

\author{
Peng Zhu ${ }^{1}$, Xiaole Zhang ${ }^{2}$, Wenjia Guo ${ }^{3 *}$ \\ ${ }^{1}$ Peng Zhu (Assoc. Prof.) Jinan University, China, 83696861@qq.com \\ ${ }^{2}$ Xiaole Zhang (Graduate Student) Jinan University, China, 978703897@qq.com \\ ${ }^{3}$ Wenjia Guo (Graduate Student) Jinan University, China, 18222581360@163.com \\ ${ }^{*}$ Corresponding Author
}

\begin{abstract}
History education is an indispensable part of humanistic education. In China, besides the traditional Chinese history, American history is also a course that students are more interested in. In the teaching of American history, the issue of immigration is a topic that can't be avoided, especially Tibetan, Miao and other immigrants are more likely to arouse students' interest. This article takes the Tibetan immigrants as an example to explain the process of the survival and development of immigrants in the United States and their changes in national characteristics, religious beliefs and other aspects. The history of Tibetan immigration is a microcosm of the history of American immigration. Tibetans have migrated to the United States for 70 years. On the one hand, their population continues to increase and their living conditions have improved. On the other hand, they also face many difficulties, such as losing their ethnic characteristics, internal differentiation, alienation of religious beliefs and so on. These problems exist not only in Tibetan immigrants, but also in other ethnic immigrants in the United States. How to help students understand these problems is important for the teaching of American history.
\end{abstract}

Keywords: History Education and Teaching; American History; Tibetan Immigrants

\section{INTRODUCTION}

In the teaching of American history, the issue of immigration is often involved, especially Tibetan, Miao and other immigrants are more likely to arouse students' interest. Taking Tibetan immigrants as an example, since the first Tibetan monk settled in the United States in 1948, the number of Tibetan immigrants in the United States has reached about 20,000. Although the population of Tibetan immigrants is not large among the numerous immigrant groups in the United States, the attention of Tibetan immigrants has been relatively high due to the repeated hype of the "Tibet issue" by the anti-China forces in the United States. In US academics, the research on Tibetan immigrants has gradually increased in the past two decades. On the whole, many researchers have ideological prejudices and still regard the so-called "Chinese aggression against Tibet" as the historical premise for ordinary Tibetans and monks to immigrate to the United States. Many research results are too fragmented, involving all aspects of Tibetan life, seemingly exhaustive, in fact, it does not reveal the common problems of Tibetan immigrants in the United States from a macro perspective. In Chinese academic circles, American Tibet policies have been the focus of research in recent years, but there are few special studies on Tibetan immigrants. This article will focus on explaining the 
process of the survival and development of Tibetan immigrants to help students understand the problems encountered in the teaching of American history.

\section{THE PROCESS OF TIBETAN IMMIGRATION TO THE UNITED STATES}

The history of Tibetan immigrants to the United States can date back to the 1940s. In 1948, Telopa Rinpoche was invited by Johns Hopkins University to teach Tibetan in the United States and became the first Tibetan to settle in the United States. Later, some Tibetan Buddhist monks, including Thubten Jigme Norbu, the eldest brother of the 14th Dalai Lama, came to the United States to teach Buddhism and Tibetology in Indiana, New Jersey, Washington and other states. In 1958, Geshe Ngawang Wangyal founded the first Tibetan Buddhist monastery in the United States in New Jersey. However, at that time, the number of Tibetans in the United States was extremely limited. Until 1967, when the Great Northern Paper Company of Maine recruited six Tibetans to work in logging, the number of Tibetan immigrants to the United States gradually increased through various channels. By 1985, the total number of Tibetan immigrants in the United States had reached 524

In the 1990s, the number of Tibetan immigrants in the United States increased significantly under the influence of changes in Tibetan-related policies of the United States. In 1990, the Tibetan United States Resettlement Project (TUSRP) was added to Section 134 of the newly revised immigration law to provide 1,000 immigration quotas for "exiled Tibetans" in South Asia. The first group of Tibetan immigrants arrived in New York on April 16, 1992, and the U.S. Government set up 21 settlements in 18 states to resettle them. Since then, more and more Tibetans have entered the United States through family reunion, religious immigration, political asylum and even material fraud and smuggling. When the "Tibetan government in exile" carried out the census in 1998, the total number of Tibetans in the United States had reached 5500 . In June 2018, American media reported that the number of Tibetan immigrants in the United States reached 21,000. Among them, New York and Twin cities have seen the fastest growth in the number of Tibetans, having become the first and second largest Tibetan settlements in the United States respectively.

Due to language barriers and lack of higher education, most early Tibetan immigrants could only do manual work in restaurants, hotels, factories, grocery stores and construction sites. With relatively low incomes, some had to take two or more part-time jobs. According to a follow-up study of the first batch of 75 Tibetan immigrants in the Madison settlement in 1995, seven of the fifteen respondents worked in restaurants and hotels, six persons cared for the elderly or disabled in medical centers, one disinfected equipment in hospitals, and one was unemployed, of which four worked two part-time jobs. A Tibetan who helps cook at a restaurant revealed that he was paid only $\$ 4.50$ an hour during his internship before rising to $\$ 5$ three months later. During the same period, the first batch 150 Tibetan immigrants in Twin Cities had much the same story. After initially 20 people hired by Hyatt Hotel, most of the rest were looking for jobs in the catering and nursing industries, many of whom worked several part-time jobs to support their families in South Asia.

After years of adaptation and accumulation, the work and life of Tibetan immigrants in the United States have been gradually improved. Some people have established their own business successively, opening restaurants with Tibetan characteristics, handicraft shops and other forms of economic entities. But overall, Tibetan immigrants are still at the bottom of American society, and there is almost no substantial improvement in the short term. Moreover, Tibetan immigrants in the United States are also faced with many difficulties in maintaining tradition, ethnic division and even confrontation, alienation of religious beliefs and so on, confronting with grim developing situation.

\section{HOW TO UNDERSTAND THE "FADING" OF ETHNIC CHARACTERISTICS}

Although the United States is a multi-cultural immigrant country, Christian culture has always maintained a strong position. Therefore, many small and weak ethnic groups are facing the risk of assimilation, and Tibetan immigrants are no exception. In the past few decades, more and more Tibetan immigrants have become real "Americans" with losing their typical features of Tibetans in both external image and internal self-identity, except for the face of the yellow race.

\subsection{Dying Signs of National Languages}

Language is not only the main tool of human communication, but also one of the basic characteristics of a nation. It is an indisputable fact that Tibetan language inheritance is difficult and shows signs of dying out, although the older generation of Tibetan immigrants in the United States has long paid more attention to maintaining the national language and culture. Locally, Tibetan immigrants mainly rely on intergenerational transmission within their families and on the teaching of "Tibetan schools" to maintain the national language. At present, there are 24 "Tibetan schools" organized by Tibetan associations or Tibetan community 
organizations in the United States. Most of these "Tibetan schools" are named "Tibetan Language and Culture School" and "Tibetan Children's School", but in fact they are not real full-time schools, for having neither permanent school buildings nor qualified teachers. They usually use the venues and facilities of churches or other institutions to run schools on weekends, while teachers are Tibetan volunteers. For example: the "Tibetan School" in Wisconsin is located in Dale Heights Presbyterian Church, Madison. The school offers courses from 9:30 to 13:30 every Saturday, mainly on Tibetan reading, writing, singing and dancing, for 48 students aged six to twenty who are divided into five classes; the "Tibetan Children's School" run by the Southern California Tibetan Association borrows the venue of Culver City town hall on Sunday for elementary and advanced classes. The actual learning effect is very limited for students to learn Tibetan in these cram "schools" on weekends, because of short learning time and long intervals.

Another important reason why the ethnic language tends to disappear among American Tibetan immigrants is the weakening of Tibetan's communicative function and the decreasing frequency of use. A small number of Tibetan immigrants are scattered among more than 300 million people in the United States, just like a drop in the ocean. To maintain their own survival and development, they inevitably need to use English as the main language of foreign exchanges, and therefore the scope and opportunities of using Tibetan language are quite limited. Even in the daily communication between Tibetan immigrants, some people are accustomed to communicating in English. This situation has not only occurred in recent years, nor is it an individual phenomenon. As early as 1992, some of the first immigrants to the United States were young Tibetans born in South Asian countries were unable to read or write Tibetan. "Sometimes they also speak English with Tibetan friends because their English is more fluent than Tibetan." What is more, the second generation of Tibetan immigrants who came to the United States with their parents or were born in the United States, have gradually adopted English as their first language and are psychologically resistant to use Tibetan after the training and cultivation of American citizens' education. According to an interview with Tibetan immigrants in New York, the influence of school education and peer interaction on the Tibetan children's formation of language habit has exceeded the role of family: on the one hand, English is the basic teaching language in the American education system, "once they enter school, they will speak English consciously"; on the other hand, "they prefer to communicate with their peers in English" in daily social activities, otherwise they will not be able to communicate with teachers and other ethnic classmates. Within the family, when they are "asked to talk to their parents in Tibetan, they often use English vocabulary." For them, learning and using Tibetan has become an additional "burden". In the long run, Tibetan immigrants, like other minorities, will find it difficult to maintain their own national language in the English-speaking country - the United States, and their "Tibetan cultural characteristics may disappear completely".

\subsection{Few National Traditions Remain}

Most of the early Tibetan immigrants in the United States had lived in South Asian countries for a long time, and they became more mobile after immigrating to the United States. In the process of migration, the original Tibetan traditions have gradually changed and even completely lost, with the constant changes of living environment and the impact of mainstream cultures. Not only the traditional customs, such as mountain circumambulation (walking and even kowtowing all the way around the holy mountain), holy-lake worship, Marnyi Stone (a unique halidom inscribed with words) and celestial burial, cannot be maintained due to the restrictions of objective conditions, but also the daily lifestyle such as diet and clothing are basically "Americanized". In diet, many Tibetan immigrants have become accustomed to the fast-food culture of the United States in order to adapt to the fast-paced and high-load work with fried food and carbonated drinks as their main meals instead of Zanba, butter tea, yak beef and other traditional foods. At the same time, Tibetan restaurants featuring ethnic foods have localized their ingredients and cooking methods to cater to the tastes of American customers. It is difficult to find authentic traditional Tibetan foods even in Jackson Heights of New York, where is the densest area of Tibetan restaurants. Although some Tibetan restaurants in Madison, Twin Cities and Los Angeles are operated by Tibetan immigrants, their meals are mainly of South Asian flavor. In terms of clothing, few Tibetan immigrants wear ethnic costumes in their daily life, so it is not easy to distinguish them from other Asian immigrants only by clothing. Except places for business or exhibition, it is rare to see Tibetans in Tibetan robes and prayer wheels (a Tibetan Buddhist prayer object, shaped like a small barrel with scriptures carved around it) even in Tibetan settlements in New York and Twin Cities. The adult Tibetan women wearing Tibetan hair accessories and apron are even rarer to see; meanwhile, the new generation of Tibetan immigrants generally rejects wearing traditional clothes in public. In the "Tibetan School" which claims to inherit the national language and culture, few students wear ethnic clothes.

The loss of national tradition is particularly evident in festivals. Festival activities can best reflect the Tibetan tradition, as Tibetans have many festivals. However, some of the festival activities of American Tibetan immigrants have been seriously "twisted" with the national traditions dying out: First, the atmosphere of 
traditional festivals has become increasingly cold. Although the number of early Tibetan immigrants was small, they paid more attention to traditional festivals and still held some celebrations under limited conditions. With the growth of living time in the United States, fewer and fewer Tibetans celebrate ethnic festivals in the traditional way due to the subtle influence of local social customs, and therefore some festivals have even been "forgotten". Instead, some Tibetans, especially young people, tend to indulge in the "foreign festivals" such as Thanksgiving, Christmas and Valentine's Day. Second, "Tibetan independence" as the purpose of the "festival" overshadows its origin. After the Tibetan rebellion, the Dalai clique set March 10 as the so-called "Rebellion Day", colluded with the anti-Chinese forces of the United States and encouraged local governments in Wisconsin, Indiana and other states to designate this day as the so-called "Tibet Day". Inspired by the Dalai Lama and "Tibetan Independence" organizations around the world, this date has become a fixed "festival" for some Tibetans who hold public activities every year to attract the attention of the outside world, and its momentum even surpasses that of the Tibetan New Year to some extent. Third, the festival activities "change its tune". Festivals organized by some Tibetan organizations in the United States are not only filled with strong political color, but also have a variety of strange program contents, in which languages of English, Hindi and Nepali can be found, and songs and dances with obvious western influence, such as rock and rap, are becoming more and more popular. All these are getting away from the Tibetan tradition. In addition, traditional etiquette, which has almost disappeared from the daily lives of Tibetan immigrants in the United States, is also rarely used during festivals.

\subsection{Decline of National Identity}

Since the late 1990s, the ethnic identity of Tibetan immigrants in the United States has been seriously reduced with the large number of Tibetan naturalization and the increase of the new generation. First is selfidentity confusion. After the US government officially accepted the first batch of "exiled Tibetan", the Dalai clique began to encourage Tibetans to naturalize in the United States in order to "enable these Tibetans to act as 'emissaries' of their lost homeland and make a political voice in the US", rather than the usual practice of restricting. However, the majority of Tibetans who apply to immigrate to the United States do not intend to speak for the Dalai clique, but to gain a better life, or just to survive. Therefore, once meeting the naturalization requirements, most people join American citizenship without hesitation. Naturalization changes not only their legal identity, but also their self-identity. In an interview conducted in 1999, some respondents were confused about whether they were "Tibetan" or "American". Some said they felt they were no longer "Tibetan" from the moment they swore allegiance to the United States.

Second is the distortion of collective identity. Misled by various propaganda of the Dalai clique, some American Tibetan immigrants, especially "exiled Tibetans" and their descendants, lack correct understanding of Tibetans and Tibetan history. So they unilaterally emphasize the independence of their own nation, do not recognize Tibetans as a part of the Chinese nation, as well as exclude new Han immigrants, who emigrate directly from the Chinese mainland to the United States, and other Tibetan immigrants, who identify with the Chinese nation. In general, they live at a certain distance from the areas where Chinese people live together. Moreover, they seldom communicate with ordinary overseas Chinese, let alone participate in all kinds of activities organized by overseas Chinese. Thus, Tibetan people are rarely seen no matter in festivals organized by overseas Chinese or in various performances from China.

Third is the transfer of regional identity. Most of the Tibetan immigrants in the United States come directly from South Asia, and many of them have left Tibetan areas in China for decades, while others have grown up entirely outside China without any experience of living in Tibetan areas in China. In consequence, their understanding of Tibetan areas in China is limited to the old impressions or intergenerational descriptions as well as information disseminated by various media, many of which are negative propaganda by the Dalai clique. These make some Tibetan immigrants in the United States lack a sense of affinity for Tibetan areas in China, especially those who grew up outside Tibet, whose sense of belonging to China's Tibetan areas is even more indifferent. Among them, some people regard India, Nepal and other south Asian countries as their "homeland", while others regard the United States as their "homeland". In a 1995 interview with 15 Tibetans in Madison, some claimed that their "homeland" was in south Asian countries. This situation has become more and more serious after entering the 21st century. Increasing Tibetan immigrants not only "mistake their hometown" but also tend to regard Tibetan settlements in South Asia as the main ethnic areas.

\section{HOW TO UNDERSTAND THE INTERNAL DIVISION OF TIBETAN IMMIGRANTS}

Affected by the instigation and incitement of Dalai Lama, the Tibetan immigrant groups in the United States have been beset by numerous conflicts and disputes over the years. They have split into different groups and camps, and even become antagonistic and irreconcilable. 


\subsection{Infinite Amplification of "Natural Difference"}

Like other immigrant groups, there are some "natural differences" among Tibetan immigrants in the United States due to their different origins and experiences, mainly including their origin and time of leaving Tibetan areas in China. Although these differences are objective facts that can not be changed by individual will, they often become the criterion to distinguish each other among Tibetan immigrants in the United States, thus affecting the unity of the whole group. American Tibetan immigrants can be roughly classified into three categories according to "natural differences": First, Tibetans have immigrated to the United States from South Asian countries, including the "exiled Tibetans" who followed Dalai after the 1959 Tibetan rebellion, the "newcomers" who moved to South Asia after the 1980s, and some descendants who are the second and third generations of Tibetans born in South Asia; Second, Tibetans who immigrated directly from the mainland of China to the United States after the reform and opening-up, have " taken root "in the United States mainly through overseas study, investment, employment, missionary work and other means; Third, descendants of Tibetan immigrants are born and raised in the United States.

In terms of numbers, Tibetans from South Asia and their descendants are the majority of Tibetan immigrants in the United States. Although they have all lived in South Asia, bad blood between them is caused by the different time they left the Tibetan area of China. The "exiled Tibetans", who followed the Dalai into South Asian countries after the 1959 Tibetan uprising, and their descendants posed as "orthodox Tibetans" before moving to the United States. They were suspicious and biased against the after-1980s "newcomers", believing that they had been "brainwashed" by the Chinese government. Some "newcomers" are even treated as "spies" and subject to strict scrutiny and surveillance. After moving from South Asia to the United States, the rift between the two has not been eliminated by the common experience. Since the official implementation of the "Tibetan-American Resettlement Plan" in 1992, the proportion of "newcomers" accepted by the United States has remained low. Therefore, and "exiled Tibetans" and their descendants have long dominated the whole Tibetan immigration group, controlling various major social resources, about which "new arrivals" have complained. On the other hand, the "newcomers" still have most of the relatives and friends in China, so they have less concern in South Asia while have relatively close contact with Tibetan areas in China. Thus they can skillfully use WeChat, $Q Q$ and other social software. Some of them are even more accustomed to communicating in Chinese. Even speaking Tibetan, many Tibetans from Qinghai, Gansu, Sichuan, eastern Tibet and Yunnan have strong local accents. The language used in Tibetan education, which is accepted by "exiled Tibetans" and their descendants, is the official Lhasa dialect of the Dalai clique, sometimes mixed with Hindi or English. In addition, the habits, hobbies and behaviors of the "newcomers" formed by their long-term life in China are also regarded as "sinicization" by the "exiled Tibetans" and their descendants. On the contrary, the "newcomers" believe that the "exiled Tibetans" and their descendants have become "Indianized" and are no longer genuine Tibetans. Such differences are magnified to the extent, which make the two sides appear to be at odds with each other.

Compared with the "newcomers" who immigrated to the United States through South Asia, "exiled Tibetans" and their descendants are more likely to exclude new Tibetan immigrants who are directly from the mainland of China. Most of these new immigrants are well-off, well-educated or have certain professional skills in China. After coming to the United States, they have low dependence on Tibetan communities. They neither agree with the Dalai clique's "Tibetan independence" proposition nor are willing to participate in the political activities of "exiled Tibetans". At the same time, they can read and write Chinese, get familiar with the tibetrelated policies of the Chinese government, understand the development and progress of Tibetan areas in China, retain many living habits in China, and have a natural affinity for the popular music, dance and other art performances in China. More importantly, they believe that China's Tibetan region is the main part of the Tibetan nation, and that the new immigrant groups they belong to are the representatives of the "orthodox Tibetans" in the United States. But "exiled Tibetans" and their descendants believe that they have been completely "sinicized" and are "Chinese" who speak the "enemy language". Therefore, the community organizations led by "exiled Tibetans" basically do not accept new Tibetan immigrants who are regarded as "Chinese". Even if some Tibetans directly from the mainland of China choose to follow the Dalai clique, they are hard to really integrate into the "exiled Tibetans" group and still suffer from suspicion and discrimination. In the various activities held by the "exiled Tibetans", participants can also use English, Hindi, Nepali and Bhutan dialects except Tibetan while Chinese is prohibited. Moreover, the "exiled Tibetans", through the Tibetan organizations they control, obstruct the contacts between other Tibetans from South Asia and new Tibetan immigrants regarded as "Chinese". In recent years, with the increasing number of Tibetan immigrants from mainland China, many Tibetan organizations have been set up in various parts of the United States to oppose "Tibetan independence" and maintain national unity. On the one hand, they send their voices to the American society, on the other hand, they stand up against the Tibetan organizations 
controlled by the Dalai clique, and fought against exclusion and suppression from "exiled Tibetans".

\subsection{Political Differences Are Difficult To Bridge}

On the whole, the most important political divergence among American Tibetan immigrants lies in whether they agree that "Tibet is an inalienable part of China" and "Tibetan is an important part of the Chinese nation". As we all know, Tibet was formally incorporated into the territory of China as early as the early years of the Yuan dynasty. Since then, the central governments of successive dynasties have exercised effective sovereign jurisdiction over Tibet. In 1951, the central government of the People's Republic of China and the local government of Tibet signed the Seventeen Articles Agreement for the peaceful liberation of Tibet. In 1954, the 14th Dalai Lama and the 10th Panchen Lama attended the first National People's Congress together in Beijing, respectively elected as the Vice-Chairman of the NPC(National People's Congress) and the Vice-Chairman of the CPPCC(National Committee of the Chinese People's Political Consultative Conference). After the Tibetan rebellion in 1959, the Dalai fled to India and used his religious influence to engage in anti-China separatist activities abroad for a long time. In the United States, the Dalai clique, through various intertwined Tibetan organizations, has continuously distorted history, slandered the Chinese government, advocated "Tibetan independence" and incited national hatred for many years, which has deeply bewitched many Tibetan immigrants and made them strong supporters of the separatist forces of "Tibetan independence". Without doubt, among American Tibetan immigrants, there are many insightful people, who firmly oppose the political views of Dalai clique and refuse to associate with its supporters. In addition, some Tibetan immigrants have never participated in various activities organized by "exiled Tibetans" and resist the political propaganda of the Dalai clique, although they have not clearly expressed their political position. Even the "exiled Tibetans" who once supported the "Tibetan independence", many of them chose to withdraw from the Tibetan organizations controlled by the Dalai clique after taking a foothold in the United States and no longer participate in anti-China political activities. For example: Lobsang Wangden, an "exiled Tibetan" from Bhutan, opted out of the Wisconsin Tibetan Association in less than three years after emigrating to Madison and said he would only like to associate with "progressive" Tibetans in the future.

As far as the supporters of "Tibetan independence" are concerned, there are also obvious differences in their political views. Among them, most of the older generation of Tibetans mostly support the "middle way" proposed by the Dalai Lama, and advocate "Tibetan independence" through peaceful negotiations; however, young people believe that it is impossible to make Tibet completely independent from China by peaceful means. They prefer the violent means advocated by radical organizations such as the "Tibetan Youth Association" and the " Students for a Free Tibet ". The older generation of Tibetans criticized the radical young Tibetans for not respecting the Dalai Lama's propositions and decisions, and confronting the Chinese government by violent means was tantamount to hitting stones with pebbles. The latter retorts that the former occupy the leading position but covet ease, and have not made any substantial progress for decades. In 2011, after Lobsang Sangay, who was the leader of the Tibetan Youth Association and studied and worked in the United States for a long time, was elected as the Kalon Tripa of the "Tibetan government-Inexile", the radical forces which advocate violent "Tibetan independence" increased their power in the United States, and the contradiction with the so-called "conservatives" who insist on the "middle way" became increasingly intensified. In 2015, serious clashes broke out between the two sides during the March 10 Parade in New York, making the internal struggles of "exiled Tibetans" in the United States completely public. In 2016, when the "Tibetan government-in-exile" held a general election, many "exiled Tibetans" were disappointed and refused to vote, as the candidates and their supporters criticized each other, revealing some previously unknown scandals. Of the more than 9,000 "exiled Tibetans" eligible to vote in New York and New Jersey, only 2,600 votes were returned. In November 2017, the "Tibetan government-in-exile" abruptly dismissed the representative of North America, Penpa Tsering, which once again triggered an internal conflict between "exiled Tibetans" in the United States. The focus of their argument was initially focused on the personal enmity between Penpa Tsering and Lobsang Sangay, and then gradually shifted to the "route dispute" between the "middle way" and the violent "Tibetan independence". With the deepening of political differences, the "exiled Tibetans" in the United States who support "Tibetan independence" have been divided into different groups, each holding his own views and fighting on his own.

\subsection{Increasing Religious Struggle}

Except the above differences and contradictions, the religious struggle caused by the exclusiveness of the Dalai clique, has further aggravated the internal division of the Tibetan immigrants group in the United States. The Dalai clique seemingly claims that all beings and religions are equal, but in fact it only respects the Gelug sect, elevates the Dalai's status infinitely among overseas Tibetans, and explicitly or implicitly 
devalues and suppresses other sects of Tibetan Buddhism. Many Tibetan organizations in the United States have long been dominated by the Gelug sect of pro-Dalai clique, therefore a few monks and laymen of other sects can hardly control the overall situation even if they can reach the top. Under the remote control of the Dalai clique, these Tibetan organizations not only ignore the actual working and living conditions of the Tibetan immigrants, and often drive them to participate in various political activities, but also impose longterm economic exploitation upon them. Every Tibetan immigrant aged from 6 to 84 in the area has to pay an "independent donation" to the Dalai clique. At the same time, they have to pay "dues" and a variety of regular or irregular "donations" to local Tibetan organizations. Tibetans in Twin Cities, for example, can become members of the Minnesota American Tibetan Foundation only after paying "independent donation" and annual fees ranging from $\$ 36$ to $\$ 300$, not including other temporary fees. The combination of various factors has made the monks and laymen of the Kargyu, Nyingma and Sakya sects increasingly dissatisfy with the Tibetan organizations controlled by the Gelug sect, which has led to the alienation and fragmentation of the whole Tibetan group. Even within the Gelug sect, the confrontation and struggle between followers of Dorje Shugden and of the Dalai clique has developed to an irreconcilable level.

Dorje Shugden's belief first appeared in the era of the Fifth Dalai Lama, a history of more than 300 years. In 1996, the Dalai Lama officially banned Tibetans from offering sacrifices to Dorje Shugden by slandering Xiongtian as a "pro-Han demon" and "evil spirit of supporting China", and forcibly labelled it "evil heaven" (which has a similar sound as Dorje Shugden in Chinese). In the United States, the Dalai clique requires Tibetan organizations at all levels not to accept the followers of Dorje Shugden, let alone allow their own followers to worship Dorje Shugden, or even to talk about Dorje Shugden openly or communicate with followers of Dorje Shugden. According to a Tibetan named Nob in Twin Cities: when Tibetans are found to have any contact with followers of Dorje Shugden or talk about Dorje Shugden, they will receive "special attention" from Tibetan community organizations. Nevertheless, many Tibetans continue to worship Dorje Shugden and publicly accuse the religious persecution from Dalai clique. Since the late 1990s, there have been protests and demonstrations held by followers of Dorje Shugden at the scene of the Dalai Lama' activities almost every time he visits the United States. During the Dalai Lama's stay in New York in November 2014, more than 500 followers of Dorje Shugden followed him to protest for two consecutive days. In July 2015, the Dalai Lama held a birthday celebration in California, which attracted thousands of Dorje Shugden's followers to protest. In recent years, as tensions between the two sides have intensified, the Tibetan immigrants who believe in Dorje Shugden and the supporters of the Dalai Lama have split into two completely opposing camps.

\section{HOW TO UNDERSTAND THE ALIENATION OF RELIGIOUS BELIEFS}

Although most Tibetan immigrants still adhere to Tibetan Buddhism, Tibetan Buddhism is no longer a pure religious belief in the United States, but a tool used by some "political Lamas" and politicians to realize their personal ambitions, or a means of profit-making and even collecting wealth. Generally speaking, the most prominent problems are as follows:

\subsection{Politicization of Religious Beliefs}

Because most Tibetan immigrants have acquired the right of legal residence in the United States or become citizens of the United States, the Dalai clique has no direct administrative jurisdiction over them. Therefore, religious beliefs have become main tool to exert political influence on American Tibetan immigrants. One is by propagating political ideas and views through religious activities. Since Dalai Lama first visit to the United States in 1979, he has visited the United States almost every year under various pretexts. From 1989 to 2009 alone, the Dalai Lama visited the United States as many as 35 times. During his stay in the United States, the Dalai Lama often carried out religious activities as a leader of the Gelug sect of Tibetan Buddhism, to instill the idea of "Tibetan independence" into Tibetan immigrants. From the content of his previous speeches, it can be inferred that the Dalai Lama in the United States has formed a fixed pattern, namely "religion provides support and services to politics", which combines Buddhist doctrine with hot issues in reality. To gain audiences' approval, Dalai Lama seemingly emphasizes the concept of human integration and advocates universal values, such as "freedom", "democracy", "human rights" and "environmental protection", but actually seeks the opportunity to peddle anti-China separatist political propositions, such as "Tibetan independence" and "Great Tibetan Area" with "high degree of autonomy and real autonomy".

Second, religious means are used to coerce believers to participate in political activities. The Tibetan organizations controlled by the Dalai clique, though bound by law of the United States, cannot force Tibetan immigrants to participate in their political activities. However, they deliberately equate the political demands of the Dalai clique with the merits and virtues of Tibetan Buddhists by confusing concepts and blurring 
boundaries. Some Tibetan immigrants, therefore, misunderstand that to support "Tibetan independence" and actively participate in anti-China political activities is to build up merit and virtue. Otherwise, they will betray the Dalai Lama and faith, and eventually suffer karma. Moreover, according to an anonymous Tibetan immigrant, those "pro-Han people" who refuse to cooperate or openly oppose "Tibetan independence" will be isolated or even cursed by local Tibetan organizations. Therefore, although most Tibetan immigrants are busy with making a living, they still have to spend money and time to participate in various activities organized by anti-China forces of "Tibetan independence". Some have lost their jobs as a result of repeated absences from work because of their frequent participation in political activities.

Third, religion education are used to convey political ideas. In order to avoid the so-called "Tibetan independence cause" having no successor, the Dalai clique and the American Tibetan organizations under its control all attach great importance to spreading the idea of "Tibet independence" among young people. Since many teenagers are not interested in pure political preaching, local Tibetan organizations mainly use religious education to convey their political views of "Tibetan independence". Most of the twenty-four "Tibetan schools" in the United States have religious courses. The "Tibetan schools" in Boston, Twin Cities and other places have clearly defined religious education as the core curriculum as equally important as language education. These religious courses, while imparting knowledge of Dharma, are invariably telling the "history" of Tibet and Tibetan Buddhism, and attribute the situation that the "exile" of the Dalai Lama and the emigration of Tibetan Buddhist monks to the United States, to "China's invasion of their homes" and "China's policy of destroying Tibetan religion".

\subsection{Commercialization of Religious Beliefs}

In the Buddhist practice system, most monks do not produce anything, so they need to rely on the alms of the other families to complete their practice. Therefore, both Theravada Buddhism and Mahayana Buddhism emphasize that monks should not collect wealth for their own use and "return" to all living beings by their merits and virtues. Tibetan Buddhism, which belongs to Mahayana Buddhism, as well as Han Buddhism, is no exception. However, Tibetan Buddhism in the United States has been used by some people for profit, especially by the Dalai clique.

The religious activities hold by Dalai clique in the United States completely copied the model of some artists' commercial performances, in which the Dalai clique made extensive publicity and bid up ticket prices during the early stage, while in the later stage, it hyped up and exaggerated the impact. During the Dalai Lama's "Promoting Dharma" in Twin Cities in 2006, every adult was required to pay $\$ 25$ and every child $\$ 10$ before meeting him collectively. Since then, the price of tickets for Tibetan believers to meet the Dalai Lama has been rising. In 2016, the price for membership of the "Minnesota American Tibetan Foundation" had risen to $\$ 30-50$, while non-members needed $\$ 50-75$ and children aged 6-17 were charged $\$ 15-50$ according to their age. Not only do the Dalai Lama frequently go to Tibetan settlements in the United States to collect money, but monks who are sent by the "Tibetan government-in-exile" to the United States to "expound the texts of Buddhism", also charge followers varying amounts of money. For example, when Jetsun Pema, the sister of the Dalai Lama and the former minister of education of the "Tibetan government-in-exile", led a monk group to Twin Cities to "promote Dharma" in 2007, seven events were held and charged everyone $\$ 15$ to $\$ 28$ for almost every event. Except the clearly priced tickets, the Dalai clique use followers' religious enthusiasm to achieve the goal of wealth by trying to induce its followers to "give external wealth" to them.

While the Dalai clique continues to come to the United States to collect money, the commercialization of Tibetan Buddhism in the United States is also increasingly strong. Not only do some monks imitate the Dalai clique in holding various religious activities to collect money from their followers, but various sects also compete to open commercialized Buddhist Dharma centers, treating religious practice as a business. According to incomplete statistics, there are already more than 1000 Buddhist Dharma centers of various forms in the United States, most of which are business organizations. For example, the Shambhala Meditation Center founded by Chögyam Trungpa Rinpoch, has five branches in Los Angeles alone, offering a two-hour course of Contentment in Everyday Life per week that costs $\$ 175$ for five weeks. Madison, the capital of Wisconsin where the economy is relatively backward and its population of only 250,000 , has six Buddhist centers. The branches of Shambhala Meditation Center in Madison, offer the same courses as in Los Angeles, which charges $\$ 110$ for five weeks. The "Diamond Sutra Meditation" courses on weekends which are offered by Luyuan Buddhist Dharma centers, charge $\$ 30$ for one day and $\$ 55$ for two days. In addition to fee-paying courses, the Kadam meditation center also hosted the Midwest Dharma Celebration in 2018. The meeting lasted for only two days while its registration fee was up to $\$ 130$. There are numerous similar examples which indicate that the commercialization of religious beliefs has become a common phenomenon in American Tibetan Buddhism. 


\section{CONCLUSION}

Over the past seventy years, although the population of Tibetan immigrants in the United States has continued to increase and their living conditions have been improved, they still overall face many difficulties, which have never been solved and ever intensified: the contradictions between integration and assimilation, unity and differentiation, as well as belief inheritance and religious alienation. On the one hand, in the process of adapting to the American society, the ethnic characteristics of Tibetan immigrants have gradually weakened. Many people can no longer read or write Tibetan, or adhere to national traditions, and have less identity of the Tibetan people. On the other hand, under the influence of the instigation and incitement of the Dalai Lama, the constantly internal conflicts and disputes among Tibetan immigrants have led them to split into different groups and camps, some of them even become antagonistic and irreconcilable. Meanwhile, Tibetan Buddhism, widely believed by Tibetans, has also undergone serious alienation, either as a tool to achieve political ambition and profit-making.

\section{REFERENCE LIST}

Barry, S. (1999), "The Tibet issue in post-summit Sino-American relations", Pacific Affairs, vol.72, no.1, p.8.

Benjamin, K. and Bessette, C. (2018), "Tibetan official visits Otis Library, thanks Norwich community for welcoming Tibetan immigrants", TCA Regional News, June 15.

Colleen, M. (2001), "Religions of the United States in practice", vol.2, Princeton University Press, p.355.

CTA. (2010), "Tibetan community in exile: integrated development plan-IV, 2009-2013", the Office of the Planning Commission, Central Tibetan Administration, pp22-24.

Dhundup, G. (2004), "Exile Tibetans in Statistics”. http://tibet.net/2004/10/12/exile-tibetans-in-statistics/.

Frank, J.K. (1999), "Tibetans in Exile: A Euro-American Perspective", Passages, vol.1, issue 1, p.13.

Gary, L. and Luis, L. (2003), "Religion and American cultures: an encyclopedia of traditions, diversity, and popular expressions", vol.1, Santa Barbara: ABC-CLIO, p.66.

Goldstein M.C. (2009), "The United States Intervenes", Journal of China Executive Leadership Academy Pudong, vol.3, no.6. p.124.

Jean, H. (2014), "Dalai Lama celebrates Tibetan New Year in Twin Cites", Star Tribune (Minneapolis, MN), Mar3.

Joan, M. (2011), "Buddhism in the United States: Implications for Managers of Buddhist Values in the Workplace", International Journal of Management, vol. 28, no. 2, pp.566-567.

Johnson, D. (1993), "Tibetans Celebrate First New Year in Minnesota”, Asian Pages, vol.3, no.14, p.1.

Jonathan, H.X. L. (2015), “Asian American religious cultures”, vol.2, Santa Barbara: ABC-CLIO, p.910.

Jonathan, H.X.L. (2011), "Encyclopedia of Asian American folklore and folklife”, vol.3, Santa Barbara: ABCCLIO, p.1139.

Julia, M.H. (2006), "Statelessness and the State: Tibetans, Citizenship, and Nationalist Activism in a Transnational World", International Migration, vol. 44, no.1, p.80.

Julia, M.H. (2009), "Immigrant Ambassadors: Citizenship and Belonging in Tibetan Diaspora”, Standford University Press, p.120.

Kinga, B. (2008), "One Home One Dream: Exploring Tibetan Diaspora in New York City", Humanity in Action, 2008. https://www.humanityinaction.org/knowledgebase/81-one-home-one-dream-exploring-tibetandiaspora-in-new-york-city.

Ling, H.P. and Allan, A. edited. (2010), "Asian American history and culture: an encyclopedia”, M.E. Sharp Inc, p.572.

Michael, B. (2003), "Buddhist Faith in America", Facts on File, p.43.

Molly Gilbert-Chatalic. (2012), "Tradition and Identity among Tibetan Americans", Caliban, issue 31, p.33. 
Nathan, L. (1995), "The Tibetan Community in Madison: Change and Continuity", University of WisconsinMadison's Archives, ID9911125615002121, pp.12-37.

Nawang, P. (2000), "Immigrant Tibetan Children in U.S. Schools: An Invisible Minority Group", Multicultural Perspectives, vol.2, issue 4, p.18.

Nolan, Z. (1999), “'Ommmmm'in Minnesota”, Star Tribune (Minneapolis, MN), Sept 4.

Nolan, Z. and Sarah T. W. (2001), "Preparing a place for Dalai Lama”, Star Tribune (Minneapolis, MN), February 27.

Norman,P. (2017), "The Tibetan Diaspora and the Politics of Belonging in the Twin Cities", PhD thesis, Middlesex University, pp.153-154,p.190,pp.230-232.

Pamela, M. (2006), "Solemn or smiling, he's a 'spring of hope'", Star Tribune(Minneapolis, MN), April 17.

Pamela, M. (2007), "From Tibet, holy sounds, honored guest", Star Tribune (Minneapolis, MN), May 5.

Patricia, M. (1991), "Tibetan Buddhism Is Adapting to American Life”, New York Times (1923-Current file), Mar 3, p.552.

Paul, L. (1997), "Home away from home”, Star Tribune (Minneapolis, MN), Jan 12.

Rebeca, G. S. and Lee, J.T.H. (2017), "A bird without wings: a conversational approach toward heritage preservation among Tibetan New Yorkers", Social Transformations in Chinese Societies, vol.13, issue 1, p.95.

Samp, K.C. (2015), "Why Thousands of Buddhists are Protesting the Dalai Lama". https://thinkprogress.org/why-thousands-of-buddhists-are-protesting-the-dalai-lama-243237505c67/.

Seonaigh, M and Anne, S.B. and Dawa, B.G. (2008), "Global Nomads: The Emergence of the Tibetan Diaspora” (Part I), September 2. https://www.migrationpolicy.org/article/global-nomads-emergencetibetan-diaspora-part-i/.

Shah, A. (2010), "Minnesota's Tibetans flock to leader's valedictory tour", Star Tribune (Minneapolis, MN), Oct 26.

Tom, H.(2007), "Dalai Lama says compassion is key: Spiritual leader talks in Madison",Milwaukee Journal Sentinel, May 5.

Yeh, E. T. (2007), "Exile meets homeland: politics, performance, and authenticity in the Tibetan diaspora", Environment and Planning D: Society and Space, vol.25, pp. 653-659.

Zhao, X.J, and Edward, J.W.P. (2014), "Asian Americans: an Encyclopedia of Social, Cultural, Economic, and Political History", vol.3, Santa Barbara: ABC-CLIO, p.1108. 